\title{
Invasive Candida Infections in the ICU: Diagnosis and Therapy
}

\author{
Péter Hankovszky, Domokos Társy, Nándor Öveges, Zsolt Molnár* \\ Department of Anaesthesiology and Intensive Therapy, University of Szeged, Albert Szent-Györgyi Health Center, \\ Szeged, Hungary
}

\begin{abstract}
Invasive fungal infections have become a serious problem in the critically ill. One of the main reasons is the development of an immunocompromised condition. The most frequently found pathogens are Candida species. In order to provide adequate treatment, understanding this potentially life-threatening infection is mandatory. The aim of this summary is to view Candida infections from a different perspective and to give an overview on epidemiology, the range of pathophysiology from colonization to the invasive infections, and its impact on mortality. New therapeutic options will also be discussed and how these relate to current guidelines. Finally, the key issue of the choice of antifungal agents will be evaluated.
\end{abstract}

Keywords: Candida, invasive Candidiasis, diagnostics, therapeutic algorihms

Received: 02 July 2015 / Accepted: 15 September 2015

\section{INTRODUCTION}

The incidence of invasive mycoses has increased five fold in the past decade caused by two underlying factors. Firstly, more and more patients with impaired immunity are being treated and secondly, prolonged stay in hospitals facilitates the development of invasive mycoses $[1,2]$. Although means of diagnosing mycoses has improved, early specific diagnosis still remains a challenge [3]. The high mortality and morbidity related to invasive fungal infections renders early adequate source a pivotal role $[4,5]$. The problem stems from the fact that clinicians often fail to consider the possible outcomes of these infections, and also that the etiology of the infection is not always adequately established. The aim of this review is to give guidance on how to develop a somewhat different way of thinking about both diagnostics and therapy. Accordingly, a brief review of the decision algorithms necessary to establish diagnosis and starting antifungal therapy will be preented, followed by guidance on choosing appropriate antifungal agents.

\section{EPIDEMIOLOGY, INCIDENCE, MORTALITY}

There are 100,000 known fungus species of which 400 are important from a medical point of view. Less than fifty of the species are human pathogens. Most of the infections are nosocomial and account for approximately $15 \%$ of healthcare related infections. Candida species are responsible for the vaste majority of fungal infections (70-90\%), followed by the Aspergillus species (1020\%) [6]. EPIC II, (2007) was a one-day, prospective point prevalence study which highlighted Candidae as the third most common pathogen, responsible for $17 \%$ of all the infections [7]. A Swiss study confirmed that one-third of candidaemia occurs in intensive care units (ICU) [8]. Candida infections occur five to ten times more often (2-6.7 in 1000 admitted patients) in ICUs than on medical or surgical wards. In the USA it is the third and fourth most common pathogen isolated from blood cultures and accounts for $8-10 \%$ of bloodstream infections. In Europe it is the sixth to tenth most commonly identified pathogen and responsible for 2-3\% of bloodstream infections [9]. According to current data, mortality rate of invasive Candida infections is considered high. Recent studies indicate it varies between 40-60\% [10-12] and within certain conditions mortality can reach $100 \%$ [5]. Epidemiology of candidae has changed in the past 20 years. While earlier candida albicans was the dominant pathogen and caused twothirds of the infections, currently increasing number of non-albicans species can be noticed and are responsi-

\footnotetext{
Correspondence to: Zsolt Molnár, University of Szeged, Faculty of Medicine, Department of Anaesthesiology and Intensive Therapy 6. Semmelweis st. 6725 Szeged, Hungary. E-mail: zsoltmolna@gmail.com

Domokos Társy: University of Szeged, Faculty of Medicine, Department of Anaesthesiology and Intensive Therapy 6. Semmelweis st. 6725 Szeged, Hungary

Nándor Öveges: University of Szeged, Faculty of Medicine, Department of Anaesthesiology and Intensive Therapy 6. Semmelweis st. 6725 Szeged, Hungary.

Zsolt Molnár: University of Szeged, Faculty of Medicine, Department of Anaesthesiology and Intensive Therapy 6. Semmelweis st. 6725 Szeged, Hungary.
} 
ble for almost $50 \%$ of the infections. These include $C$. glabrata, C. krusei, C. tropicalis and C. parapsilosis [13]. There are several other factors, which can affect the occurrence of different candida species. While Candida glabrata is more common among elderly people, Candida parapsilosis is more common in Australia, SouthAmerica and Southern Europe than in North-America or Northern Europe [13]. Characteristics of the different Candida species are shown in Table 1 [14].

\section{DATHOMECHANISM OF INVASIVE INFEC- TIONS, ENDANGERED PATIENTS AND RISK FACTORS}

Since different candida species are part of the normal skin and mucous membrane flora, including oropharyngs, vagina and colon, colonization can occur already

Table 1. Characteristics of common non-albicans species

\section{Species}

C. glabrata

c. parapsilosis

C. tropicalis

\begin{tabular}{ll}
\hline & Use of piperacillin/tazobactam, vanco- \\
& mycin \\
Innate resistance to fluconazole & Haematological malignancies \\
C. krusei & Neutropenia \\
& Recent gastrointestinal surgery \\
& Fluconazole exposure
\end{tabular}

Less susceptible to echinocandins

C. guiillermondi Less susceptible to fluconazole Intravascular catheters

The table was imported from Paramythiotou E et al: Invasive Fungal Infections in the ICU: How to Approach, How to Treat [14], CVC $=$ Central venous catheters, $T P N=$ Total Parenteral Nutrition in the newborns during the birth process. Colonization is not harmful among healthy subjects, however candida species can overgrow the normal flora through changes in the microbiom associated with among others, antibiotic therapy, burn injury, neutropenia and diabetes mellitus, and additionaly certain predisposing factors such as weak natural immunity, impaired cellular immunity, diabetes mellitus, and pregnancy. These factors can predispose to an invasive candida infections. Different impacts on deep tissues can lead to micro-invasion due to barrier damage, and a possible source of candidaemia. Although this does not necessarily progress in all cases to severe sepsis or septic shock, it can cause dissemination of the mycoses initiating endophtalmitis, hepatosplenic, CNS, infective endocarditis or abscesses in different organs and tissues, and subsequently the establishment of severe sepsis.

An important clinical issue is to identify which patients are more susceptible to invasive candida infection. The most susceptible patients are those with imparied immunity, but several other medical conditions should be taken into account. These are summarised in Table 2 and 3.

Table 2. Endangered patients who are more susceptible to Candida infection

\begin{tabular}{ll}
$\begin{array}{l}\text { Impaired immunity } \\
\text { Oncology }\end{array}$ & $\begin{array}{l}\text { Other medical conditions } \\
\text { Hollow organ perforation }\end{array}$ \\
\hline Haemato-oncology & Great abdominal surgery \\
\hline Febrile neutropenia & $\begin{array}{l}\text { Urologic intervention with } \\
\text { parallel candiduria }\end{array}$ \\
\hline Neutropenia & Polytrauma \\
\hline HIV, AIDS & Malnutrition \\
\hline $\begin{array}{l}\text { Immunosuppressive } \\
\text { therapy }\end{array}$ & Severe pancreatitis \\
$\begin{array}{l}\text { Burn injury, where more } \\
\text { than 50\% of body surface } \\
\text { is affected }\end{array}$ & ICU \\
\hline
\end{tabular}

Table 3. Risk factors in terms of Candida infection

\begin{tabular}{ll} 
High risk & Non-specific risk \\
\hline Multiple colonization & Elderly age $>65$ years \\
\hline Broad spectrum AB therapy & Diabetes mellitus \\
\hline TPN & Renal failure \\
\hline Dialysis & Surgical intervention \\
\hline APACHE II $>20$ points & Foley catheter \\
\hline CVC & Catheters inserted to ves- \\
\hline Candiduria $>105 c f u / m l$ & sels \\
\hline & Long ICU stay $>7$ days \\
\hline CVC=Central venous catheters, TPN = Total Parenteral Nutrition
\end{tabular}




\section{FROM COLONISATION TO INFECTION}

Candida colonisation and infection are two closely related consecutive events which can occur following illness. On admission to an ICU only $5-15 \%$ of the patients were reported to have candida colonisation, however this number increases to $50-80 \%$ during their stay in ICU. Only 5-30\% of these patients developed an invasive candida infection [16]. Multifocal colonisation is common among ICU patients, mainly among those who have spent more than seven days on the ICU. The most commonly loci are the stomach (45.6\%), oropharyngeal samples $(34.3 \%)$, the trachea (23.4\%), perirectal region (21.2\%) and the urinary tract (18.7\%). Recent studies show that the relative risk of invasive candidiasis was significantly higher in those patients whose faecal samples ( $7.5 \%$ vs. $3.2 \%, \mathrm{p}=0.019)$ or urine samples $(9.2 \%$ vs. $5.2 \%, \mathrm{p}=0.032)$ were positive. Multifocal colonisation was found to be an independent risk factor of invasive candidiasis. Pursuant to these results patients should be screened (faeces, urine, tracheal aspirate) twice a week enabeling the clinicians to identify patients at high risk of invasive candida infection. Samples taken from other locations such as the stomach, skin, or pharynx, should also be taken into account $[17,18]$. Colonization can be low or high. The latter occurs if at least three samples are positive on two or more consecutive occasions [19].

Invasive candidiasis is a collective term which includes several indicators.

- Primary candidaemia is said to exist if one or more blood cultures taken from peripheral venous boold are positive for the fungus.

- Intra-abdominal candidiasis is said to exist if candida is detected in peritoneal fluid obtained by direct punction or from an intra-operative sample, or from a sample taken through an intra-abdominal drain, inserted within the past 24 hours, or when a direct microscopic examination confirms fungal yarns.

- A mixed form candidiasis can consist of the elements constituting primer and intra-abdominal candidiasis. This group includes one-third of the patients.

Most cases of invasive candidiasis occur between five to twelve days in an ICU. It is essential to differentiate between catheter-related candidaemia and primer or intra-abdominal candidiasis-related candidaemia, since the latter has lower morbidity and mortality. Di- agnosis of this can be established if the catheter sample and the peripheral blood sample confirms the same candida species. Rare manifestations of invasive candidiases exist i.e. endophtalmitis, endocarditis, meningitis, pleural, bone and joint or hepatosplenic candidiasis. According to recent knowledge, colonisation of the GI tract (endogene path) has a prominent role in development of primary candidiasis while cases of catheter-related candida infections occur through the exogene path and are in relation with colonisation of the patient's skin and of the healthcare workers' hands [16].

Invasive candidiases can be separated into three groups: proven, probable or possible. Differentiation is based on cultures, biomarkers, clinical picture and the patient's individual risk factors [16,20,21]. Infection is confirmed if proliferous fungal presence is proven from blood or infected tissue samples and microbiologic examination identify candida species in obtained samples. Infection is proven if both histology and microbiology identify proliferous fungal presence from blood or infected tissue samples. Infection is probable if a compromised patient who has been in the ICU for a prolonged period has heavily colonised severe sepsis or septic shock and positive for mannan, 1-3 beta-d-glucan, a known serum biomarker for candidemia. Infection is possible if an endangered patient who has been in an ICU for a prolonged period has heavily colonised severe sepsis or septic shock but negative biomarkers.

\section{DIAGNOSTICS}

Numerous options are available for diagnosis, however none is perfect in itself. These include different scoring systems to assess risk, and highly sophisticated laboratory measures to identify the pathogen. These must be combined, as systemic candidiasis is often accompanied with no candidemia, thus risk adapted empiric antifungal therapies play a crucial role in treating invasive candidiases [22,23].

\section{Risk scores and prediction rules}

\section{Colonisation index}

Colonisation and its degree has a crucial role in the development of invasive candida infection. In a study by Pitett et al [19], 29 severely colonised patients were investigated, of whom eleven had documented invasive candidiasis. The colonisation index was 0.47 in patients with no infection and 0.7 in patients with infection 
$(p<0.01)$. The cut-off value of colonisation index was defined as $>0.5$ which predicted the presence of invasivity six days earlier than microbiologic cultures. This was confirmed by several subsequent studies [15,2426]. The negative predictive value of colonisation index is $100 \%$, its positive predictive value is $66 \%$ [27], with a sensitivity of $64 \%$ and a specificity of $69.7 \%$ [25].

According to this, the dynamics and degree of colonisation can be established through periodical screening of samples taken from the nose, throat, armpit, loin, submammal region, stomach, faeces, trachea aspirate and urine. It is advisable to perform screening among endangered patients or patients with risk factors, once or twice a week. Colonisation index can be calculated from the number of samples taken from non-sterile regions idivided by the total number of samples. If the colonisation index exceeds the cut-off value $(>0.5)$ consideration should be given to commensing empiric antifungal therapy.

\section{Candida score}

The "Candida Score" [León et al, 2006] is an upgraded version of the Colonisation Index [28], based on a prospective cohort study enrolling 1699 patients, out of which 97 (6\%) had invasive candidiasis. The results of this study indicated that surgery [odd ratio (OR): 2.71; 95\% confidence interval $(\mathrm{Cl}): 1.45-5.06]$, multifocal colonisation (OR: 3.04; 95\% CI: 1.45-6.39) and severe sepsis (OR: 7.68; 95\% CI: 4.14-14.22) are predictors of invasive candidiasis. One point was allocated for each of these predictive factors in the candida score (except for severe sepsis, to which 2 points were allocated). A Candida score higher that 2,5 points has a sensitivity of $81 \%$, a specificity of $74 \%$, a negative predictive value of $98 \%$ and a positive predictive value of $16 \%$ for predicting invasive candidiasis. Its clinical adaptability was confirmed by several studies $[25,29,30]$. However, there are no prospective clinical studies examining the applicability of Candida Score as a guideline to start empiric antifungal therapy.

\section{Ostrosky-Zeichner formula}

This prediction formula was meant to identify patients who require antifungal profilaxis when in an ICU. In a study undertaken in a surgical ICU [31], the incidence of invasive candidiasis was found to be higher among those patients who spent four or more days in the ICU, had diabetes mellitus, required acute haemodialysis, total parenteral nutrition or broad spectrum antibiotic therapy, compared to those who did not belong to any of the aformentioned groups. The incidence of invasive candida infection in the two groups was $16.6 \%$ compared to $5.5 \%(\mathrm{p}=0.001)$. Seventy eight $\%$ of these patients who later developed candidaemia or invasive candidiasis were identified by this method. Several further investigations reported similar results (Table 4).

\section{Non-culture-based methods}

Culture-based diagnostic methods have a low sensitivity of approximately 50\% [34], become positive relatively late [35] and they are inadequate for diagnosing deep-seated candidiasis. Moreover, histopathologic methods, body fluid punctures and tissue biopsies are invasive and often clinically contraindicated, making them unavailable in everyday practice [15]. Therefore it is necessary to develop specific diagnostic methods with high sensitivity, which are applicable for quick recognition of invasive candida infections. These include cellular wall components, antigenes, antibodies and methods to identify circulating fungal DNA.

Table 4. Summary of predictive (Ostrosky-Zeichner) formulas

\begin{tabular}{|c|c|c|}
\hline $\begin{array}{l}\text { Population, invasive } \\
\text { Candidiasis }\end{array}$ & Risk-based prediction model & $\begin{array}{l}\text { Accuracy of } \\
\text { prediction }\end{array}$ \\
\hline $\begin{array}{l}2890 \text { patients }[88(3 \%) \\
\text { with proven or probable } \\
\text { IC] staying } \geq 4 \text { days in nine } \\
\text { US/Brazilian ICUs }\end{array}$ & $\begin{array}{l}\text { Predictive rule }- \text { both systemic antibiotics and central venous catheter } \\
\text { (day 1-3 of ICU stay); plus two of total parenteral nutrition (day } 1-3 \text { of } \\
\text { ICU stay), dialysis (day 1-3 of ICU stay), major surgery (day }-7 \text { to } 0 \text { of } \\
\text { ICU stay), pancreatitis (day }-7 \text { to } 0 \text { of ICU stay), steroids (day }-7 \text { to } 3 \text { of } \\
\text { ICU stay), other immunosuppressive agents (day }-7 \text { to } 0 \text { of ICU stay) }\end{array}$ & $\begin{array}{l}\text { Captured } 34 \% \text { of IC } \\
\text { Sensitivity }=34 \% \\
\text { Specificity }=90 \% \\
\text { PPV }=10 \% \\
\text { NPV }=97 \%\end{array}$ \\
\hline $\begin{array}{l}97 \text { ICU patients }[22(4 \%) \\
\text { with proven or probable } \\
\text { IC] staying } \geq 4 \text { days in six } \\
\text { US ICUs }\end{array}$ & $\begin{array}{l}\text { Predictive rule: all of: mechanical ventilation, broad-spectrum antibi- } \\
\text { otics and central venous catheter (day 1-3 of ICU stay); plus one of: } \\
\text { total parenteral nutrition (day 1-3 of ICU stay), dialysis (day 1-3 of ICU } \\
\text { stay), major surgery (day }-7 \text { to } 0 \text { of ICU stay), pancreatitis (day }-7 \text { to } 0 \\
\text { of ICU stay), steroids (day }-7 \text { to } 3 \text { ), other immunosuppressive agents } \\
\text { (day }-7 \text { to } 0 \text { of ICU stay) }\end{array}$ & $\begin{array}{l}\text { Captured } 90 \% \text { of IC } \\
\text { Sensitivity }=90 \% \\
\text { Specificity }=48 \% \\
\text { PPV }=6 \% \\
\text { NPV }=99 \%\end{array}$ \\
\hline
\end{tabular}




\section{(1,3)-b-D-Glucan}

Detection of 1,3-b-D-Glucan (BDG) from the bloodstream was first published by Obayashi et al. in 1995 [36]. Subsequent investigations proved that BDG is an early biomarker of fungal infections [37-39] (except for zygomycetes and cryptococcoses which fungis cellular walls do not contain BDG). Different multicenter studies have also confirmed that a cut-off value of $80 \mathrm{pg} / \mathrm{ml} \mathrm{can}$ detect and verify invasive candida infection with good sensitivity and specificity. The test had lower sensitivity and specificity in cases of candida parapsilosis [39]. Nevertheless, it gave positive results ten days before the establishment of a clinical diagnosis of fungal infctions. It seems, that BDG is an adequate indicator of fungal infections hence a reliable biomarker for starting preemptive anti-fungal therapy. Unfortunately the BDG test is relatively costly and needs properly equipped laboratories. The test can give false positive results, mainly in the first three days of being admitted to an ICU, and especially after surgical interventions, immunglobulin therapy, or in cases treated by certain antibiotics for bacterial infections, such as mainly Streptococcus Pneumoniae. At the same time, it can cross-react with haemodialysis membranes, gauze albumin or other blood products. The results might also confirm invasive mould fungus infection [40]. Correlation between BDG levels, clinical outcome and treatment response is evidence based [41]. Data about BDG kinetics are lacking, although the results of two studies $[30,42]$ show that decreasing BDG serum levels refer to therapeutic success. If these results are confirmed by further clinical investigations, monitoring BDG levels could be used for assessing antifungal therapy. The test is useful for measuring BDG levels in other body fluids such as cerebro-spinal [43], peritoneal fluid [44], or bronchoalveolar secretions [45]. However validation of these methods will be necessary in the future. The European Organization for Research and Treatment of Cancer/Invasive Fungal Infections Cooperative Group and the National Institute of Allergy and Infectious Diseases Mycoses Study Group (EORTC/ MSG)], the European Society of Clinical Microbiology and Infectious Diseases (ESCMDI) (candidemia: level evidence II), the Society of Critical Care Medicine (SCCM), European Society of Intensive Care Medicine (ESICM) (IC: Grade 2 B), and the Expert Panel (IAC: $\mathrm{BII}$ ) all include BDG testing in their recommendations.

\section{Mannan antigene and anti-mannan antibody}

Mannan is a polysacharid component of candida cell wall, which circulates in the bloodstream in case of in- vasive candidiases. Currently latex agglutination and enzyme immunoassay-based methods are in practice for mannan detection [46]. Combined examinations give the best results which means parallel detection of mannan antigene and anti-mannan antibody (Mn-anti-Mn). According to a meta-analisys published in 2010 containing 14 studies - 7 of which included non-neutropenic critically ill patients, the sensitivity of mannan and anti-mannan investigations were 58\% and $93 \%$ while their specificity were $59 \%$ and $83 \%$ separately. In cases of Candida albicans, glabrata and tropicalis infections, when these investigations were combined, their sensitivity and specificity improved (83\% and 86\%) [47]. The European Society of Clinical Microbiology and Infectious Diseases (ESCMID) and the Surviving Sepsis Guidelines suggest the performance of a double test with C II evidence in these cases. The cause of the low quality of evidence is that most studies were retrospective and examined heterogeneous patient groups. To clarify the test's role in everyday practice further investigations are necessary, examining homogeneous patient groups, defining the positive and negative predictive values and deciding wether simple or multiple positive results are needed to assert the diagnosis of invasive candida infection.

\section{Detection of candida nucleic acids by PCR}

Fungal DNA detection by PCR technics is challenging. Human cell lysis leading to DNA "disengagement" can give false positive results. Exogene contamination from saprophytic or pathogen fungi can also lead to false positive results. Detailed discussion of the difficulties of PCR techniques is beyond the scope of this summary. PCR techniques are capable of early detection of candidaemias and have been widely studied. In a review published by Khot in 2009 [48] the following observations were reported:

- The method is appropriate for early detection of candidaemia.

- PCR is appropriate or detection of organic fragments mainly if it aims a multicopy gene.

- PCR detects non-viable organisms faster than cultures.

- Different platforms, blood samples and target genes are used during the test.

In a later meta-analisys, 4894 patients of 54 studies were examined among who 963 had proven/probable or possible invasive candidiasis. Overall sensitivity and specificity of PCR in detection of invasive candidiasis were $95 \%$ and $92 \%$ [49]. 
In those cases when invasive candidiasis was possible, sensitivity of blood cultures and PCR were markedly different, $85 \%$ and $38 \%$. PCR is certainly a significantly finer method and detects presence of invasive candidiasis earlier than blood cultures [50].

Direct molecular detection of Candidae from human samples is not a standard method and until it is not valid the place of PCR or other molecular methods in early detection of invasive candidiases remains uncertain.

\section{Culture-based diagnostics}

This group includes blood and other culture tests which are considered as the gold standard. Blood culture tests are appropriate and essential microbiologic methods of candidaemia detection. However blood cultures have also several pitfalls. If we assume candidiasis in our patients, a single sample of $40 \mathrm{ml}$ of blood coud be insufficient because the sensitivity of the test is very low. According to the current recommendation $60 \mathrm{ml}$ of blood obtained by peripherial blood punction should be distributed in 3-3 different aerobic and anaerobic containers. This should be repeated daily and the containers should be incubated for a minimum of five days. According to current experience, the sensitivity of blood cultures is around $50-70 \%$. This sensitivity may decrease in patients with neutropenia or during ongoing antifungal therapy [3]. In the case of suspected catheter related infections, samples should also be taken from the catheters to establish a source control. Although blood cultures are an essential part of the diagnostics they cannot be classified as early diagnostic strategies.

In cases of positive culture results for candida species, resistance tests should also be performed, and is important to note that minimal inhibitory concentration (MIC) values can also influence the therapy. The identification of the candida species may take several days after the detection of positive results, however it can be accelerated by some special techniques such as the PNA-FISH (Peptide Nucleic Acid Fluorescence In Situ Hybridization) and MALDI-TOF MS (Matrix Assisted Laser Desorption Ionization Time-of-Flight Mass Spectrometry). Following blood culture positivity with the PNA-FISH technique, the five most common candida species can be identified in ninty minutes by colour coding, which can also help in choosing the right antifungal agent (Candida albicans and parapsilosis are coloured in green, Candida tropicalis in yellow, Candida glabrata and krusei in red) [51]. MALDI-TOF MS is a rapid, accurate and low-cost method for identification and characterization of microorganisms. This technology can help to create large spectrum of "fingerprints" which is specific and unique for each micro-organism. The method is perfectly applicable for the identification of the microbes' genus and species levels and also very useful for characterization of fungi [52]. Samples other than blood can also be used for identification of pathogens with MALDI-TOF MS.

\section{- THERAPEUTIC STRATEgIES IN THE TREAT- MENT OF INVASIVE CANDIDIASIS}

The timing of antifungal therapy in invasive candidiasis is a major factor in terms of outcome. Several studies have proved that a delayed therapy has a negative effect on survival $[5,53-56]$. When to commence therapy is closely related to the diagnostic steps and associated possibilities. Four strategies, prophylaxis, pre-emtive, empirical and targeted therapy are outlined.

\section{Prophilaxis}

The aim of prophylactic antifungal therapy is preventing infection in those who are at high-risk of developing an invasive candida infection. For prophylactic therapy fluconazole is used in general but recently echinocandins have also been successfully used [57]. Although the use of prophylaxis is well defined among transplanted and haematological patients [3], it is seldom recommended for use in ICU patients $[3,21]$. Of course there are certain situations where some groups of patients may benefit from prophylactic treatment $[3,58]$ but further studies are needed to clarify this aspect. The current European recommendations for nonneutropenic patients are summarized in Table 5 [3].

\section{Pre-emptive therapy}

According to the ESCMID definition [3], pre-emptive therapy means that there is microbiological evidence of invasive candidasis but the clinical signs of fungal infection are missing. Usually these infections belong to the "possible" or "probable" categories. The microbiological evidence is based on the 1-3 beta- $\mathrm{D}$-glucan biomarker, mannan-antimannan double test or detection of fungal nucleic acid by the PCR test. In addition to the biomarkers, the patients' risk factors also need to be assessed and various score systems must be taken into consideration when starting such therapy. The current European recommendations for pre-emptive antifungal therapy in non-neutropenic patients is given in Table 6 [3]. 
Table 5 ESCMID recommendation for antifungal prophylaxis in adult non-neutropenic patients [3]

\begin{tabular}{|c|c|c|c|c|}
\hline Population & Intention & Intervention & SoR & QoE \\
\hline $\begin{array}{l}\text { Recent abdominal surgery AND recurrent- } \\
\text { gastrointestinal perforations or anastomotic } \\
\text { leakages }\end{array}$ & $\begin{array}{l}\text { To prevent intra-abdom- } \\
\text { inal Candida infection }\end{array}$ & $\begin{array}{l}\text { Fluconazole } 400 \mathrm{mg} / \text { day } \\
\text { Caspofungin 0/50 mg/day }\end{array}$ & B & II \\
\hline $\begin{array}{l}\text { Critically ill surgical patients with an expected } \\
\text { length of ICU stay } ¥ 3 \text { day }\end{array}$ & $\begin{array}{l}\text { To delay the time to } \\
\text { fungal infection }\end{array}$ & Fluconazole 400 mg/day & C & II \\
\hline $\begin{array}{l}\text { Ventilated for } 48 \mathrm{~h} \text { and expected to beventi- } \\
\text { lated for another } ¥ 72 \mathrm{~h}\end{array}$ & $\begin{array}{l}\text { To prevent invasive can- } \\
\text { didiasis/candidaemia }\end{array}$ & Fluconazole 100 mg/day & C & I \\
\hline $\begin{array}{l}\text { Ventilated, hospitalized for } ¥ 3 \text { day, received } \\
\text { antibiotics, CVC, and } ¥ 1 \text { of: parenteral nutrition, } \\
\text { dialysis, major surgery, pancreatitis, systemic } \\
\text { steroids, immunosuppression }\end{array}$ & $\begin{array}{l}\text { To prevent invasive can- } \\
\text { didiasis/candidaemia }\end{array}$ & Caspofungin 50 mg/day & C & II \\
\hline Surgical ICU patients & $\begin{array}{l}\text { To prevent invasive can- } \\
\text { didiasis/candidaemia }\end{array}$ & Ketoconazole 200 mg/day & D & I \\
\hline $\begin{array}{l}\text { Critically ill patients with risk factors for invasive } \\
\text { candidiasis/candidaemia }\end{array}$ & $\begin{array}{l}\text { To prevent invasive can- } \\
\text { didiasis/candidaemia }\end{array}$ & Itraconazole 400 mg/day & D & 1 \\
\hline Surgical ICU with catabolism & $\begin{array}{l}\text { To prevent invasive can- } \\
\text { didiasis/candidaemia }\end{array}$ & Nystatin 4 Mio IU/day & D & I \\
\hline
\end{tabular}

\section{Empirical therapy}

According to the ESCMID definition [3], empirical, fever driven, therapy is when the patient is at-risk of fungal infections with persistent fever but has no microbiological evidence of invasive candidiasis, supported by increased risk scores. Current European recommendations for empirical antifungal therapy in non-neutropenic patients are summarized in Table 6 [3].

\section{Targeted therapy}

When the sensitivity to different anticandida agents and the MIC (minimal inhibitory concentration) of the Candida species grown from blood culture or other specimen is known, the treatment can be adapted in order to achieve superior results and targeted therapy.

\section{CHOICE OF THE ANTIFUNGAL AGENT AND LENGTH OF THERAPY}

The antifungal agents administered to patients are affected by several factors and circumstances. On the one hand there are a number of national and international guidelines which can help in choosing the appropriate agents. However these guidelines cannot be applied for all clinical scenarios. There are several factors affecting when and what species can be responsible for the invasive candida infection in a particular patient $[13,14]$. On the other hand, we need to consider local epidemiology and resistance profiles. The antifungal drug's spectrum for drugs are given in Table 7.

In addition we should also be aware on the MIC values (this E-testing can be only carried out in case of

Table 6. ESCMID recommendation for pre-emptive and empirical therapy in adult non-neutropenic patients [3]

\begin{tabular}{|c|c|c|c|c|}
\hline Population & Intention & Intervention & SoR & QoE \\
\hline $\begin{array}{l}\text { Adult ICU patients with fever despite broad- } \\
\text { spectrum antibiotics and APACHEII >16 }\end{array}$ & To resolve fever & $\begin{array}{l}\text { Fluconazole } 800 \\
\text { mg/day }\end{array}$ & $\mathrm{D}$ & I \\
\hline $\begin{array}{l}\text { ICU patients persistently febrile, but without- } \\
\text { microbiological evidence }\end{array}$ & To reduce overall mortality & $\begin{array}{l}\text { Fluconazole or } \\
\text { echinocandin }\end{array}$ & C & II \\
\hline $\begin{array}{l}\text { ICU patients with candida isolated from respi- } \\
\text { ratory secretions }\end{array}$ & $\begin{array}{l}\text { To cure invasive candidiasis } \\
\text { or candidaemia early }\end{array}$ & Any antifungal & $\mathrm{D}$ & ॥ \\
\hline ICU patients with positive $(1,3)-b-D$-glucantest & $\begin{array}{l}\text { To cure invasive candidiasis } \\
\text { or candidaemia early }\end{array}$ & Any antifungal & C & II \\
\hline $\begin{array}{l}\text { Any patient with Candida isolated from a blood } \\
\text { culture }\end{array}$ & To cure invasive candidiasis & $\begin{array}{l}\text { Antifungal treat- } \\
\text { ment }\end{array}$ & A & II \\
\hline
\end{tabular}


Table 7. Antifungal activity spectrum and Candida species [59]

\begin{tabular}{|c|c|c|c|c|c|c|c|c|}
\hline Candida spp. & AMB & FLU & ITRA & VOR & POSA & CAS & MIC & ANI \\
\hline C.albicans & ++ & ++ & ++ & ++ & ++ & ++ & ++ & ++ \\
\hline C.glabrata & + & $+/-$ & $+/-$ & + & + & ++ & ++ & ++ \\
\hline C.parapsilosis & ++ & ++ & ++ & ++ & ++ & + & + & + \\
\hline C.tropicalis & ++ & ++ & ++ & ++ & ++ & ++ & ++ & ++ \\
\hline C.krusei & + & - & $+/-$ & + & + & ++ & ++ & ++ \\
\hline C.rugosa & + & + & + & ++ & ++ & + & + & + \\
\hline C.guilliermondii & ++ & ++ & ++ & ++ & ++ & + & + & + \\
\hline C.lusitaniae & ++ & ++ & ++ & ++ & ++ & ++ & ++ & ++ \\
\hline C.inconspicua & ++ & - & + & + & + & ++ & ++ & ++ \\
\hline C.norvegensis & ++ & - & $+/-$ & $+/-$ & $+/-$ & ++ & ++ & ++ \\
\hline
\end{tabular}

micafungin, ANI anidulafungin

fully known species of Candida). The sensibility degree to the antifungal agent, expressed in points, can be interpreted in accordance with the EUCAST (European Committee on Antimicrobial Susceptibility Testing) or CLSI (Clinical and Laboratory Standards Institute) database.

The current European recommendations for antifungal therapy in non-neutropenic adult patients is given in Table 8 [3].

The duration of the therapy is influenced by many factors and current recommendations are mainly based on consensus rather than clear evidence. Basically, in case of a positive blood culture for a candida species, empiric antifungal therapy should be started immediately followed by obtaining daily blood cultures.
According to current recommendations, the patient should be treated for a minimum of fourteen additional days after the first negative culture results have been recorded. De-escalation is also possible or a switch to oral therapy after ten days, after taking into account the existing clinical picture [3]. In cases of deep-seated candidiasis, the therapy should be continued for a longer period. In these cases the clinical picture and the source of infection determine the choice of the antifungal agent and the length of therapy. If candidaemia is present, ophthalmological examination and transthoracic or transesophageal echocardiography is mandatory in all cases to exclude intraocular candidiasis and infective endocarditis. The infected intravascular catheters must be removed as soon as possible. If this

Table 8. ESCMID recommendation for antifungal therapy [3]

\begin{tabular}{|c|c|c|c|}
\hline Intervention & SoR & QoE & Comment \\
\hline Anidulafungin 200/100 mg & A & 1 & $\begin{array}{l}\text { Consider local epidemiology (Candida parapsilosis, Candida } \\
\text { krusei), less drug-drug interactions than caspofungin }\end{array}$ \\
\hline Caspofungin 70/50 mg & A & I & Consider local epidemiology (C. parapsilosis) \\
\hline Micafungin 100 mg & A & I & $\begin{array}{l}\text { Consider local epidemiology (C. parapsilosis), less drug-drug } \\
\text { interactions than caspofungin, }\end{array}$ \\
\hline Amphotericin B liposomal 3 mg/kg & B & I & $\begin{array}{l}\text { Similar efficacy as micafungin, higher renal toxicity than mica- } \\
\text { fungin }\end{array}$ \\
\hline Voriconazole $6 / 3 \mathrm{mg} / \mathrm{kg} /$ day & B & I & $\begin{array}{l}\text { Limited spectrum compared to echinocandins, drug-drug } \\
\text { interactions, limitation of IV formulation in renal impairment, } \\
\text { consider therapeutic drug monitoring }\end{array}$ \\
\hline Fluconazole 400-800 mg & C & I & $\begin{array}{l}\text { Limited spectrum, inferiority to anidulafungin (especially in the } \\
\text { subgroupwith high APACHE scores), may be better than echino- } \\
\text { candins against C. parapsilosis }\end{array}$ \\
\hline Amphotericin B lipid complex 5 mg/kg & $\mathrm{C}$ & II & - \\
\hline $\begin{array}{l}\text { Amphotericin B deoxycholate 0.7-1.0 } \\
\mathrm{mg} / \mathrm{kg}\end{array}$ & D & I & Substantial renal and infusion-related toxicity \\
\hline
\end{tabular}


Available online at: www.jccm.ro

is not possible then echinocandin, liposomal or lipid complex amphotericin-B must be started because they are also able to diffuse into the biofilm [3].

\section{DUMMARY}

The increasing number of invasive fungal infections are a real and important problem in critically ill patients. Although significant progress has been made in both the diagnostics and therapy over the last years, invasive fungal infections are still often overlooked. Early diagnosis and antifungal therapy without delay are the only chances that can improve the chances for survival of these patients. According to our present knowledge the preemptive therapy may be the most promising approach. Applying biomarkers and fungal DNA tests can improve diagnostic accuracy and makes early treatment possible. Nevertheless, there are several issues to be solved in the future including both diagnostics, therapy and determination of the length of treatment.

\section{REFERENCES}

1. Pfaller MA, Diekema DJ. Epidemiology of invasive mycoses in North America. Crit Rev Microbiol. 2010;36:1-53.

2. Lepak A, Andes D. Fungal sepsis: optimizing antifungal therapy in the critical care setting. Crit Care Clin. 2011;27:123-47.

3. Ullmann AJ, Cornely OA, Donnelly JP, et al. ESCMID guideline for the diagnosis and management of Candida diseases 2012: developing European guidelines in clinical microbiology and infectious diseases. Clin Microbiol Infect. 2012;Suppl 7:1-77.

4. Pfaller MA, Diekema DJ. Epidemiology of invasive candidiasis: a persistent public health problem. Clin Microbiol Rev. 2007;20:133-63.

5. Kollef M, Micek S, Hampton N, Doherty JA, Kumar A. Septic shock attributed to Candida infection: importance of empiric therapy and source control. Clin Infect Dis. 2012;54:1739-46.

6. Delaloye J, Calandra T. Invasive candidiasis as a cause of sepsis in the critically ill patient. Virulence. 2014;5:161-9.

7. Vincent JL, Rello J, Marshall J, et al. EPIC II Group of Investigators. International study of the prevalence and outcomes of infection in intensive care units. JAMA. 2009;302:2323-9.

8. Marchetti O, Bille J, Fluckiger U, et al. Fungal Infection Network of Switzerland. Epidemiology of candidemia in Swiss tertiary care hospitals: secular trends, 1991-2000. Clin Infect Dis. 2004;38:311-20.

9. Méan M, Marchetti O, Calandra T. Bench to bedside review: Candida infections in the intensive care unit. Crit Care. 2008;12:204.

10. Guery BP, Arendrup MC, Auzinger G, et al. Management of invasive candidiasis and candidemia in adult non-neutropenic
The Journal of Critical Care Medicine 2015;1(4) • 137

intensive care unit patients: Part I. Epidemiology and diagnosis. Intensive Care Med. 2009;35:55-62.

11. Leroy O, Gangneux JP, Montravers P, et al. Epidemiology, management, and risk factors for death of invasive Candida infections in critical care: a multicenter, prospective, observational study in France (2005-2006). Crit Care Med. 2009;37:1612-8.

12. Falagas ME, Apostolou KE, Pappas VD. Attributable mortality of candidemia: a systematic review of matched cohort and casecontrol studies. Eur J Clin Microbiol Infect Dis. 2006;25:419-25.

13. Arendrup MC. Epidemiology of invasive candidiasis. Curr Opin Crit Care. 2010;16:445-52.

14. Paramythiotou E, Frantzeskaki F, Flevari A, Armaganidis A, Dimopoulos G. Invasive fungal infections in the ICU: how to approach, how to treat. Molecules. 2014;19:1085-119.

15. Eggimann P, Bille J, Marchetti O. Diagnosis of invasive candidiasis in the ICU. Ann Intensive Care. 2011;1:37.

16. León C, Ostrosky-Zeichner L, Schuster M. What's new in the clinical and diagnostic management of invasive candidiasis in critically ill patients. Intensive Care Med. 2014;40:808-19.

17. León C, Alvarez-Lerma F, Ruiz-Santana S, et al. Fungal colonization and/or infection in non-neutropenic critically ill patients: results of the EPCAN observational study. Eur J Clin Microbiol Infect Dis. 2009;28:233-42.

18. Magill SS, Swoboda SM, Johnson EA, et al. The association between anatomic site of Candida colonization, invasive candidiasis, and mortality in critically ill surgical patients. Diagn Microbiol Infect Dis. 2006;55:293-301.

19. Pittet D, Monod M, Suter PM, Frenk E, Auckenthaler R. Candida colonization and subsequent infections in critically ill surgical patients. AnnSurg. 1994;220:751-8.

20. De Pauw B, Walsh TJ, Donnelly JP, et al. Revised definitions of invasive fungal disease from the European Organization for Research and Treatment of Cancer/Invasive Fungal Infections Cooperative Group and the National Institute of Allergy and Infectious Diseases Mycoses Study Group (EORTC/MSG) Consensus Group. Clin Infect Dis. 2008;46:1813-21.

21. Scudeller L, Viscoli C, Menichetti F, et al. An Italian consensus for invasive candidiasis management (ITALIC). Infection. 2014;42:263-79.

22. Hsu DI, Nguyen M, Nguyen L, Law A, Wong-Beringer A. A multicentre study to evaluate the impact of timing of caspofung in administration on outcomes of invasive candidiasis in nonimmunocompromised adult patients. J Antimicrob Chemother. 2010;65:1765-70.

23. Morrell M, Fraser VJ, Kollef MH. Delaying the empiric treatment of candida bloodstream infection until positive blood culture results are obtained: a potential risk factor for hospital mortality. Antimicrob Agents Chemother. 2005;49:3640-5.

24. Caggiano G, Puntillo F, Coretti C, et al. Candida colonization index in patients admitted to an ICU. Int J Mol Sci. 2011;12:7038-47.

25. Posteraro B, De Pascale G, Tumbarello M, et al. Early diagnosis of candidemia in intensive care unit patients with sepsis: a 
prospective comparison of $(1 \rightarrow 3)-\beta-D$-glucan assay, Candida score, and colonization index. Crit Care. 2011;15:R249.

26. Eggimann P, Pittet D. Candida colonization index and subsequent infection in critically ill surgical patients: 20 years later. Intensive Care Med.2014;40:1429-48.

27. Eggimann P, Que YA, Revelly JP, Pagani JL. Preventing invasive candida infections. Where could we do better? J Hosp Infect. 2015;89:302-8.

28. León C, Ruiz-Santana S, Saavedra P, et al. A bedside scoring system ("Candida score") for early antifungal treatment in nonneutropenic critically ill patients with Candida colonization. Crit Care Med. 2006;34:730-7.

29. León C, Ruiz-Santana S, Saavedra P, et al. Usefulness of the "Candida score" for discriminating between Candida colonization and invasive candidiasis in non-neutropenic critically ill patients: a prospective multicenter study. Crit Care Med. 2009;37:1624-33.

30. Tissot F, Lamoth F, Hauser PM, et al. $\beta$-glucan antigenemia anticipates diagnosis of blood culture-negative intraabdominal candidiasis. Am J Respir Crit Care Med. 2013;188:1100-9.

31. Paphitou NI, Ostrosky-Zeichner L, Rex JH. Rules for identifying patients at increased risk for candidal infections in the surgical intensive care unit: approach to developing practical criteria for systematic use in antifungal prophylaxis trials. Med Mycol. 2005;43:235-43.

32. Ostrosky-Zeichner L, Sable C, Sobel J, et al. Multicenter retrospective development and validation of a clinical prediction rule for nosocomial invasive candidiasis in the intensive care setting. Eur J Clin Microbiol Infect Dis. 2007;26:271-6.

33. Ostrosky-Zeichner L, Pappas PG, Shoham S, et al. Improvement of a clinical prediction rule for clinical trials on prophylaxis for invasive candidiasis in the intensive care unit. Mycoses. 2011;54:46-51.

34. Reiss E, Morrison CJ. Nonculture methods for diagnosis of disseminated candidiasis. Clin Microbiol Rev. 1993;6:311-23.

35. Morris AJ, Byrne TC, Madden JF, Reller LB. Duration of incubation of fungal cultures. J Clin Microbiol. 1996;34:1583-5.

36. Obayashi T, Yoshida M, Mori T, et al. Plasma (1-->3)-beta-Dglucan measurement in diagnosis of invasive deep mycosis and fungal febrile episodes. Lancet. 1995;345:17-20.

37. Ellis $M$, Al-Ramadi B, Finkelman $M$, et al. Assessment of the clinical utility of serial beta-D-glucan concentrations in patients with persistent neutropenic fever. J Med Microbiol. 2008;57:287-95.

38. Ostrosky-Zeichner L, Alexander BD, Kett DH, et al. Multicenter clinical evaluation of the (1-->3) beta-D-glucan assay as an aid to diagnosis of fungal infections in humans. Clin Infect Dis. 2005;41:654-9.

39. Pickering JW, Sant HW, Bowles CA, Roberts WL, Woods GL. Evaluation of a (1->3)-beta-D-glucan assay for diagnosis of invasive fungal infections. J Clin Microbiol. 2005;43:5957-62.

40. Ostrosky-Zeichner L, Kullberg BJ, Bow EJ, et al. Early treatment of candidemia in adults: a review. Med Mycol. 2011;49:113-20.
41. Takesue $\mathrm{Y}$, Kakehashi $\mathrm{M}$, Ohge $\mathrm{H}$, et al. Combined assessment of beta-D-glucan and degree of candida colonization before starting empiric therapy for candidiasis in surgical patients. World J Surg. 2004;28:625-30.

42. Jaijakul S, Vazquez JA, Swanson RN, Ostrosky-Zeichner L. $(1,3)-\beta$-D-glucan as a prognostic marker of treatment response in invasive candidiasis. Clin Infect Dis. 2012;55:521-6.

43. Lyons JL, Thakur KT, Lee R, et al. Utility of measuring (1,3)- $\beta$-dglucanin cerebrospinal fluid for diagnosis of fungal central nervous system infection. J Clin Microbiol. 2015;53:319-22.

44. Ginocchio F, Verrina E, Furfaro E, Cannavò R, Bandettini R, Castagnola $E$. Case report of the reliability $1,3-\beta$-D-glucan monitoring during treatment of peritoneal candidiasis in child receiving continuous peritoneal dialysis. Clin Vaccine Immunol. 2012;19:626-7.

45. Mutschlechner W, Risslegger B, Willinger B, et al. Bronchoalveolar Lavage Fluid $(1,3) \beta$-D-Glucan for the Diagnosis of Invasive Fungal Infections in Solid Organ Transplantation: A Prospective Multicenter Study. Transplantation. 2015;99:e1404.

46. Schuetz AN. Invasive fungal infections: biomarkers and molecular approaches to diagnosis. Clin Lab Med. 2013;33:50525.

47. Mikulska M, Calandra T, Sanguinetti M, Poulain D, Viscoli C, Third European Conference on Infections in Leukemia Group. The use of mannan antigen and anti-mannan antibodies in the diagnosis of invasive candidiasis: recommendations from the Third European Conference on Infections in Leukemia. Crit Care. 2010;14:R222.

48. Khot PD, Fredricks DN. PCR-based diagnosis of human fungal infections. Expert Rev Anti Infect Ther. 2009;7:1201-21.

49. Avni T, Leibovici L, Paul M. PCR diagnosis of invasive candidiasis: systematic review and meta-analysis. J Clin Microbiol. 2011;49:665-70.

50. McMullan R, Metwally L, Coyle PV, et al. A prospective clinical trial of a real-time polymerase chain reaction assay for the diagnosis of candidemia in nonneutropenic, critically ill adults. Clin Infect Dis. 2008;46:890-6.

51. Heil EL, Daniels LM, Long DM, Rodino KG, Weber DJ, Miller $\mathrm{MB}$. Impact of a rapid peptide nucleic acid fluorescence in situ hybridization assay on treatment of Candida infections. Am J Health Syst Pharm. 2012;69:1910-4.

52. Saracli MA, Fothergill AW, Sutton DA, Wiederhold NP. Detection of triazole resistance among Candida species by matrix-assistedlaser desorption/ionization-time of flight massspectrometry (MALDI-TOF MS). Med Mycol. 2015;53:73642.

53. Skrobik Y, Laverdiere M. Why Candida sepsis should matter to ICU physicians. Crit Care Clin. 2013;29:853-64.

54. Morrell M, Fraser VJ, Kollef MH. Delaying the empiric treatment of candida bloodstream infection until positive blood culture results are obtained: a potential risk factor for hospital mortality. Antimicrob Agents Chemother. 2005;49:3640-5. 
Available online at: www.jccm.ro

55. Garey KW, Rege M, Pai MP, et al. Time to initiation of fluconazole therapy impacts mortality in patients with candidemia: a multiinstitutional study. Clin Infect Dis. 2006;43:25-31.

56. Blot SI, Vandewoude KH, Hoste EA, Colardyn FA. Effects of nosocomial candidemia on outcomes of critically ill patients. Am J Med. 2002;113:480-5.

57. Senn L, Eggimann P, Ksontini R, et al. Caspofungin for prevention of intra-abdominal candidiasis in high-risk surgical patients.
The Journal of Critical Care Medicine 2015;1(4) • 139 Intensive Care Med. 2009;35:903-8.

58. Bassetti M, Marchetti $M$, Chakrabarti A, et al. A research agenda on the management of intra-abdominalcandidiasis: results from a consensus of multinational experts. Intensive Care Med. 2013;39:2092-106.

59. Maubon D, Garnaud C, Calandra T, Sanglard D, Cornet M. Resistance of Candida spp. to antifungal drugs in the ICU: where are we now? Intensive Care Med. 2014;40:1241-55. 